RASĀYAN J. Chem.

Vol. 13 | No. 1 |210 - 214| January - March | 2020 ISSN: 0974-1496 | e-ISSN: 0976-0083 | CODEN: RJCABP

RJC http://www.rasayanjournal.com http://www.rasayanjournal.co.in

\title{
ASSESSMENT OF TOXIC METALS IN COMMON FOOD GRAINS GROWN IN JODHPUR CITY
}

\author{
Pallavi Mishra*, Rajshri Soni, Vandana Kachhwaha and Naresh Giri \\ Department of Chemistry, JNV University, Jodhpur, 342001, Rajasthan, India \\ *E-mail: pallavianuk@gmail.com
}

\begin{abstract}
Jodhpur is the second largest city of Rajasthan and is famous for its handicrafts, tie and dye printing, steel products manufacturing and textile industries. Due to water scarcity, many farmers are using industrial effluents from these industries for growing different food grains. In this paper, we have reported an analysis of heavy metal contents in food grains grown in the agricultural fields of Jodhpur around the Jojari River. We have collected samples from various sites around the Jojari River where industrial effluents are thrown without treatment and are readily used by the farmers. We have used an atomic absorption spectrophotometer (AAS) for our analysis. Our study reveals an alarmingly high concentration of toxic heavy metals in different agricultural products. The concentration of lead and cadmium was found to be much higher than WHO/FAO recommended permissible limits. Such food grains, when consumed by us, may cause cancer, skin allergies, peptic ulcers, acidity etc. We strongly recommend pollution control authorities to take immediate measures in setting up CETP in every industry and imposing fine in throwing untreated effluent to the Jojari River.
\end{abstract}

Keywords: Jojari River, Industrial Effluents, Heavy Metals, AAS, CETP

ORASĀYAN. All rights reserved

\section{INTRODUCTION}

Vegetables and cereals are essential for a healthy and balanced diet. They provide us minerals, vitamins, essential amino acids and fibers. ${ }^{1}$ Cereals have been the main component of the human diet since primitive times because of their large scale cultivation, blend flavor and a wide variety. ${ }^{2}$ Cereals serve as a reliable source of energy and minerals to human beings as they are rich in carbohydrates, trace elements, vitamins and protein. ${ }^{3}$ In Rajasthan, cereals and millets are the major source of nutrients and the most commonly consumed food. Approximately 85 percent of the population is vegetarian and mainly survives on millets, cereals and pulses. Indira Gandhi canal water is the main source of potable water and agricultural produce. Rains are observed only in the monsoon season; otherwise almost drought conditions prevail throughout the year. Due to water scarcity industrial effluents and sewage water is used for irrigation in many areas of Jodhpur City especially around the Jojari River which has become a dumping ground for all kinds of wastewater. Continuous effluent water irrigation of agricultural land has caused a large buildup of poisonous heavy metals in the effluent irrigated soil ${ }^{4}$ as well as in the food grains, vegetables grown here.

\section{Sample Collection}

\section{EXPERIMENTAL}

Triticum aestivum, Pennisetum typhoideum, Sorghum vulgare, Hordeum vulgare, Zea mays, Vigna radiata, Vigna aconitifolia, Cajanus cajan, Lens culinary and Cicer arietinum were collected from different sites of the sampling area and stored in the labeled polythene sampling pouches. They were brought to our chemistry laboratory at New Campus, Jai Narayan Vyas University, Jodhpur. All the samples were washed under tap water to remove any kind of deposition like soil or any other foreign particles. All the seeds of millets, cereals and pulses were then oven-dried and grounded into powdered form and then digested in the acids.

\section{Preparation of Samples}

$1 \mathrm{~g}$ of each sample was weighed and digested in a mixture of $\mathrm{HCl}, \mathrm{H}_{2} \mathrm{SO}_{4}$ and $\mathrm{HNO}_{3}(5: 2: 20)$ in a conical flask. Thorough mixing was done with constant stirring by using a glass rod and was heated for 30 Rasayan J. Chem., 13(1), 210-214(2020)

http://dx.doi.org/10.31788/RJC.2020.1315570

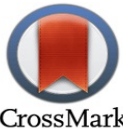


RASĀYAN J. Chem.

Vol. 13 | No. 1 |210 - 214| January - March | 2020

minutes on a hot plate at $250{ }^{\circ} \mathrm{C}$ and then was cooled to room temperature. This sample was transferred into a $100 \mathrm{ml}$ volumetric flask. Distilled water was added up to the mark to make up the volume. Samples were filtered. Blank solutions were prepared for all the samples. All chemicals used were of analytical grade. The $1000 \mathrm{ppm}$ stock solution of all metal ions was prepared and required dilutions were made for attaining calibration curves. Samples and blank solutions were analyzed on Atomic Absorption Spectrophotometer and all heavy metal concentrations were determined. ${ }^{5,6}$

\section{RESULTS AND DISCUSSION}

Heavy metals are difficult to discard from the environment as they persist for a very long time. The heavy metal concentrations in different grains varied from species to species ${ }^{7}$. All the species of the cereals, millets and pulses are listed in Table-1. The concentration of metals obtained in the contaminated cereals, millets and pulses are shown in Table-2.

Table-1: List of Food Grains taken from the affected Areas for the analysis

\begin{tabular}{c|c|c|c}
\hline S. No. & Names of the Food Grains & Botanical Names of the Food Grains & Plant Family \\
\hline 1 & Genhu (Wheat) & Triticum aestivum & Poaceae \\
\hline 2 & Bajra (Pearl millet) & Pennisetum typhoideum & Poaceae \\
\hline 3 & Juar (Sorghum) & Sorghum vulgare & Poaceae \\
\hline 4 & Jau (Barley) & Hordeum vulgare & Poaceae \\
\hline 5 & Makka (Corn) & Vea mays & Poaceae \\
\hline 6 & Moong ki daal & Vigna aconitifolia & Fabacea \\
\hline 7 & Moth ki daal & Cajanus cajan & Fabacea \\
\hline 8 & Arhar ki daal (Pigeon pea) & Lens culinary & Fabacea \\
\hline 9 & Masoor ki daal (Red lentil) & Cicer arietinum & Fabacea \\
\hline 10 & Chana daal (split chickpea lentil) & &
\end{tabular}

Table-2: Heavy Metal Concentration (in ppm) found in the Contaminated Food Grains

\begin{tabular}{c|c|c|c|c|c|c}
\hline Sample & $\mathrm{Cu}$ & $\mathrm{Cr}$ & $\mathrm{Cd}$ & $\mathrm{Pb}$ & $\mathrm{Zn}$ & $\mathrm{Ni}$ \\
\hline Wheat & 0.472 & 0.109 & 0.146 & 1.504 & 124.301 & 0.247 \\
\hline Pearl millet & 0.673 & 0.218 & 0.075 & 3.361 & 96.216 & 0.396 \\
\hline Sorghum & 0.292 & 0.137 & 0.110 & 1.792 & 82.920 & 0.418 \\
\hline Barley & 0.559 & $\mathrm{ND}$ & 0.173 & 4.475 & 103.334 & 0.395 \\
\hline Corn & 0.283 & 0.128 & 0.231 & 3.696 & 109.116 & 0.267 \\
\hline Mung bean & 0.845 & 0.202 & 0.184 & 2.752 & 73.072 & 0.463 \\
\hline Moth bean & 0.864 & 0.018 & 0.129 & 3.365 & 115.015 & 0.413 \\
\hline Pigeon pea & 0.366 & 0.289 & 0.221 & 4.409 & 92.260 & 0.284 \\
\hline Red lentil & 0.641 & 0.227 & 0.251 & 2.313 & 80.708 & 0.208 \\
\hline $\begin{array}{c}\text { Split chickpea } \\
\text { lentil }\end{array}$ & 0.906 & 0.141 & 0.167 & 1.666 & 59.432 & 0.272 \\
\hline
\end{tabular}

The metal ion concentrations obtained in our samples were compared with the permissible limits as prescribed by WHO and FAO. The graphs between the samples of the cereals, millets, pulses and various heavy metal ion concentrations found in them are also plotted below. The graphs below show heavy metal concentration in the contaminated cereals, millets and pulses.

\section{Chromium}

Chromium is one of the eight metals in the top 50 toxic substances in the world as per the guidelines issued by ATSDR (Agency for Toxic Substances and Disease Registry) and WHO (World Health Organization). $\mathrm{Cr}$ is used on a large scale in the steel factories as a component of iron-based alloys such as stainless steel and tin-free steel because it is less expensive than tin steel. Chromium is also used in medical and dental implants, bridges, appliances and tools. Chromium provides a protective corrosionresistant oxide layer on the surface of an alloy. ${ }^{8}$ Intake of excess chromium by food can cause kidney, liver, gastrointestinal, neurological, cardiac, and reproduction disorders in human beings. It can also cause 
RASĀYAN J. Chem.

Vol. 13 | No. 1 |210 - 214| January - March | 2020

inflammation and ulceration in the stomach and small bowel lesions. In our analysis maximum chromium concentration was found in Pigeon pea which is $0.289 \mathrm{ppm}$ as shown in the Table-2 and graph (Fig.-2). Overall $\mathrm{Cr}$ concentration ranged between $0.018-0.289 \mathrm{ppm}$.

\section{Cadmium}

Cadmium is released into the atmosphere by anthropogenic activities. Two major sources of cadmium contamination are the production and utilization of cadmium in different industries. The disposal of wastes containing cadmium increases Cd-contents in the soil which in tern results in an increase in the Cd-uptake by the plants. The Cd-uptake by plants from soil is higher at low soil $\mathrm{pH} .{ }^{9}$ The IARC (International Agency for Research on Cancer) has classified cadmium and cadmium compounds in the group (1) carcinogenic metals to humans. Sources of cadmium contamination in our environment are mining, electroplating, smelting and other industrial activities. ${ }^{10}$ High $\mathrm{Cd}$ concentration in plants causes reduced growth ,overall yield, changes in the chloroplast ultrastructure and initiation of oxidative stress in plants. ${ }^{11}$ The food chain is the major source of entry of cadmium to humans, especially the non-smoking population. ${ }^{12}$ In our analysis, the $\mathrm{Cd}$ concentration ranged from $0.075-0.251 \mathrm{ppm}$ in all samples, which is shown in Table-2 and graph (Fig.-3). The order of Cd concentration in our sample was: red lentils $>$ corn $>$ pigeon pea $>$ mung bean $>$ barley.

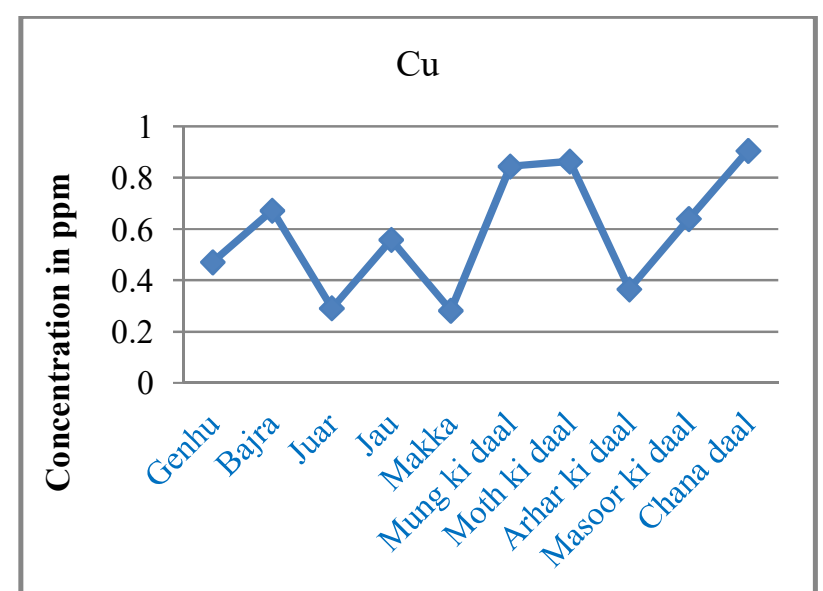

Fig.-1: Concentration of Copper

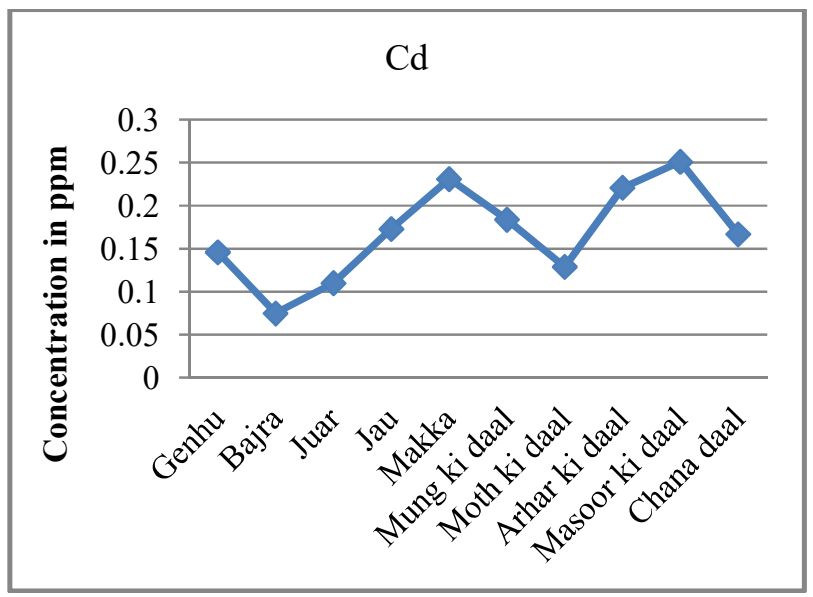

Fig.-3: Concentration of Cadmium

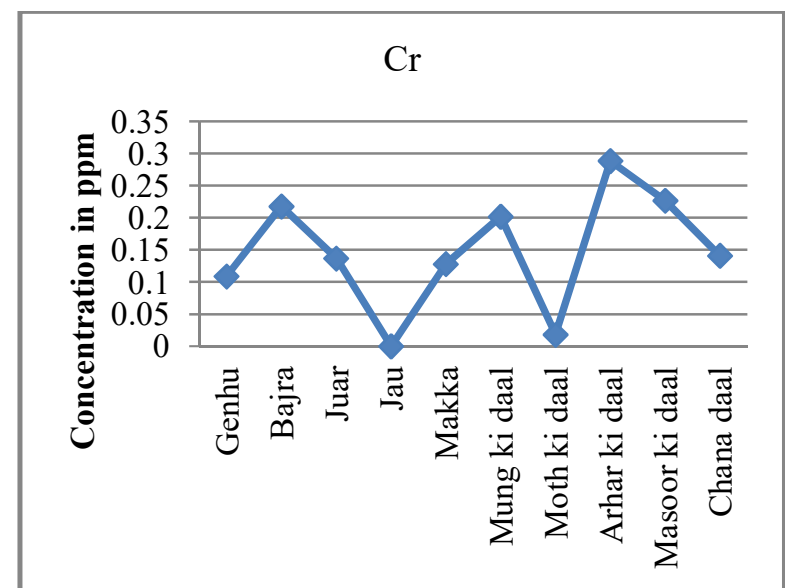

Fig.-2: Concentration of Chromium

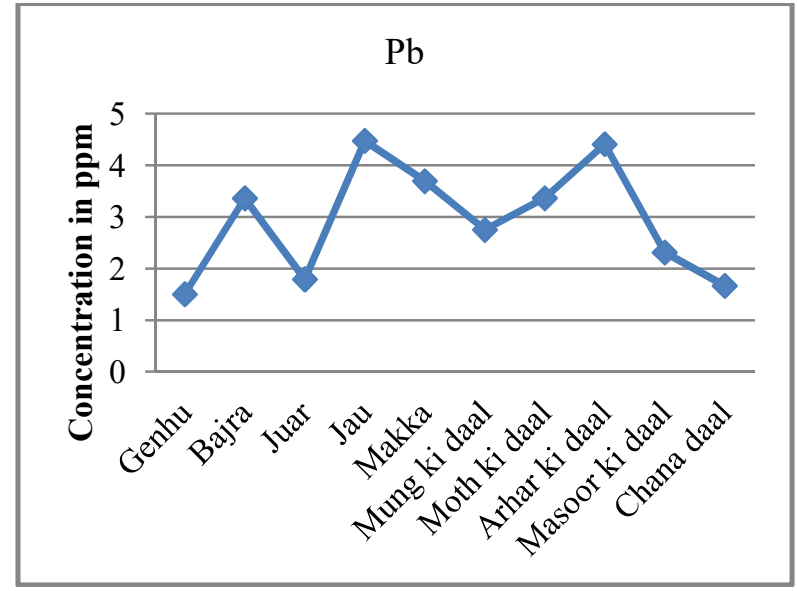

Fig.-4: Concentration of Lead

Lead

Fuel emission from vehicles, smoke and dust emissions by chimneys, thermal power stations, use of $\mathrm{Pb}$ containing paints and anti-corrosion agents are the main sources of lead pollution in our environment. Vegetables and fruits are among the foodstuffs that contribute most to the consumption of lead ${ }^{13}$. Even 
RASĀYAN J. Chem.

Vol. 13 | No. 1 |210 - 214| January - March | 2020

short term exposure to high levels of lead can cause fatal harm to the human body like brain damage, paralysis, anemia and gastrointestinal symptoms. Long-term exposure of lead can cause damage to various organ systems like excretory, reproductive and immune systems in addition to the effects on the nervous system. The most dangerous effect of low-level lead exposure is on intellectual development in young children. It decreases their IQ level. Lead can also cross the placental barrier and can accumulate in the fetus. Infants and young children are more vulnerable than adults to the toxic effects of $\mathrm{Pb}$. Short term effects of lead exposure at a very low concentration of lead can also damage and affect the nervous system. ${ }^{14}$ In our studies, $\mathrm{Pb}$ concentration was found to be in the range of $1.504-4.475 \mathrm{ppm}$ as shown in the Table-2 and graph (Fig.-4). Order of lead concentration in our samples was: barley $>$ pigeon pea $>$ corn $>$ moth bean $>$ pearl millet.

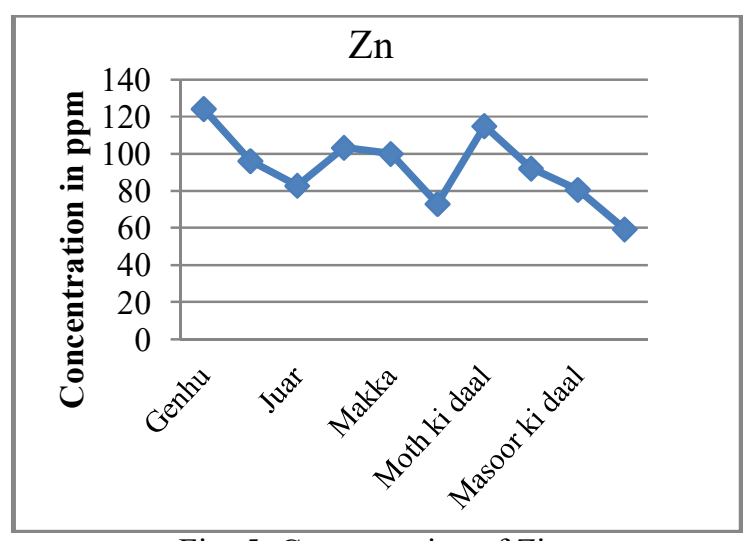

Fig.-5: Concentration of Zinc

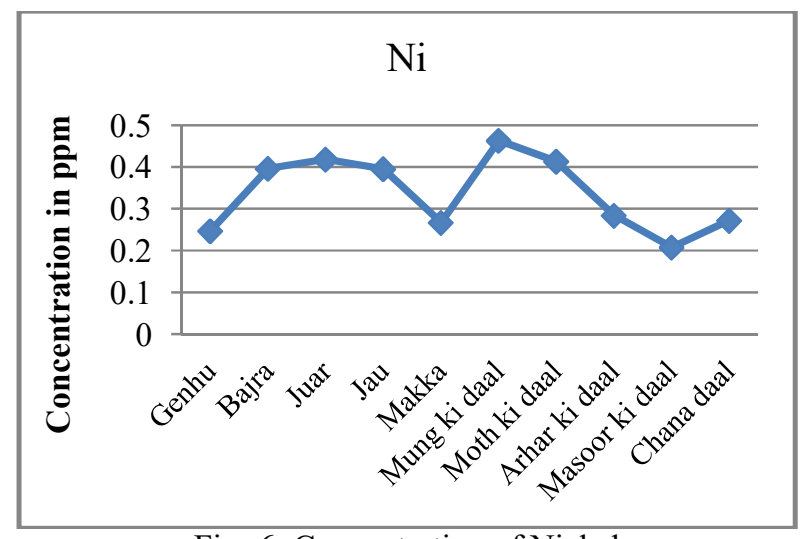

Fig.-6: Concentration of Nickel

\section{Copper}

Copper, when consumed in excess, may cause vomiting, hematemesis, low blood pressure, coma, jaundice and gastrointestinal distress. ${ }^{15}$ Long term copper exposure can damage the liver and kidneys. ${ }^{16}$ Although mammals have efficient mechanisms to regulate copper storage but higher concentrations of $\mathrm{Cu}$ may result in mood swings, irritability, depression, fatigue, excitation, difficulty in focusing. ${ }^{17}$ In the analysis of our samples, the maximum concentration of copper was 0.906 and the minimum was $0.283 \mathrm{ppm}$, which is shown in Table-2 and graph (Fig.-1). Order of Cu concentration in our samples was: chana daal $>$ moth bean $>$ mung bean $>$ pearl millet $>$ masoor ki daal.

\section{Zinc}

$\mathrm{Zn}$ is an essential trace of heavy metal with very low toxicity in humans. Excessive absorption of $\mathrm{Zn}$ can suppress $\mathrm{Cu}$ and $\mathrm{Fe}$ absorption. High $\mathrm{Zn}$ intake may cause nausea, body pain, vomiting, cramps and diarrhea in humans. The recommended dietary allowance is $15 \mathrm{mg} \mathrm{Zn} /$ day ${ }^{18,}{ }^{19} \mathrm{In}$ our sample analysis concentration of $\mathrm{Zn}$ (in ppm) ranged between $59.43-124.30 \mathrm{ppm}$ which is shown in Table-2 and graph ( Fig.-5). Order of $\mathrm{Zn}$ concentration in our samples was: wheat $>$ moth bean $>$ corn $>$ barley $>$ pearl millet.

\section{Nickel}

Nickel is an essential micronutrient for our body. Nickel is widely used in the fields of medicine, electrical engineering, automotive industry and jewelry. Harmful effects of nickel are hepatotoxicity, immunotoxicity and teratogenicity. Nickel makes its way to the human body via a respiratory canal, digestive system and skin. ${ }^{20}$ In our samples Nickel concentrations ranged from 0.208 to $0.463 \mathrm{ppm}$ which is shown in Table-2 and graph (Fig.-6). The order of Ni concentration in our samples was - mung bean $>$ sorghum $>$ moth bean $>$ pearl millet.

\section{CONCLUSION}

After carrying out samples testing of different grains we found alarmingly high concentrations of $\mathrm{Cd}, \mathrm{Pb}$, $\mathrm{Cu}, \mathrm{Cr}, \mathrm{Zn}$, and $\mathrm{Ni}$. The concentrations of six heavy metals in this study were found to be well above the standards specified by the World Health Organization and Indian Council of Medical Research. Even a slight high concentration is very dangerous for human beings and animals. An increasing number of cancer cases, gastrointestinal problems, skin problems in the people living in the areas from where 


\section{RASĀYAN J. Chem.}

Vol. 13 | No. 1 |210 - 214| January - March | 2020

samples were collected have also been reported. We recommend immediate stopping of use of industrial effluents for irrigation and recommend authorities to impose fines on the industries which are not using common effluent treatment plants so that the life of human beings can be saved. Public awareness should also be increased towards the harmful effects of eating toxic cereals, millets, pulses and vegetables.

\section{ACKNOWLEDGMENT}

We are thankful to the Chemistry Department, Jai Narain Vyas University Jodhpur for providing laboratory facilities and MNIT, Jaipur for their logistic support. We would also like to thank people of Jodhpur, who provided wholehearted support during the sampling process. This research was supported by UGC New Delhi.

\section{REFERENCES}

1. Abaidya Nath Singh, Devendra Mohan, Anjali Shukla, Pankaj Kumar, Archives of Hygiene Sciences, 6(2), 160(2016), DOI:10.29252/archhygsci.6.2.160

2. Md. Saiful, Md. Kawer, Md. Habibullah-Al-Mamum, Journal of Agricultural and Food Chemistry, 62, 10828(2014), DOI:10.1021/jf502486q

3. Doe ED, Awua AK, Gyamfi OK, Bentil NO, American Journal of Applied Chemistry,1(2), 17(2013), DOI: $10.11648 /$ j.ajac.20130102.11

4. Jaishree, T. I. Khan, International Journal of Innovative Research in Science, Engineering and Technology, 4(7), 5142(2015), DOI: 10.15680/IJIRSET.2015.0407014

5. N. Shobha and B. M. Kalshetty, Rasayan Journal of Chemistry, 10(1), 124(2017), DOI: 10.7324/RJC.2017.1011575

6. Anjula Asdeo and Sangeeta Loonker, Research Journal of Environmental Toxicology, 5, 125(2011), DOI:10.3923/rjet.2011.125.

7. I. Hoxha, N. Shala and G. Q. Xhabiri, Rasayan Journal of Chemistry, 11(2), DOI: 10.31788/RJC.2018.1123024

8. Risco Taufik Achmad, Budiawan and ELza Ibrahim Auerkari, Annual Research \& Review in Biology, 13(2), 1(2017), DOI:10.9734/ARRB/2017/33462.

9. Leila Tavakkoli, Zahra Zamani Nasab, Narges Khanjani, Journal of Epidemiological Research, 3(2), 31(2017), DOI:10.1515/reveh-2016-0042

10. Environmental Health Criteria for Cadmium, International Programme on Chemical Safety (IPCS), (1992).

11. Akiko Ike, Rutchadaporn Sriprang, Hisayo Ono, Yoshikatsu Murooka, Mitsuo Yamashita, Chemosphere, 66(9), 1670(2007), DOI:10.1016/j.chemosphere.2006.07.058

12. C. Wang, Q. Sun, L. Wang, Environmental Toxicology, 24, 271(2009), DOI:10.1002/tox.20429

13. Mercury, Lead, Cadmium, Tin and Arsenic in Food, Toxicology Factsheet Series, Food Safety Authority of Ireland, Issue No. 1, (2009).

14. R. N. Monastero, C. Vacchi-Suzzi, C. J. Marsit, B. Demple and Meliker, Toxics, 6(3), 1(2018), DOI: 10.3390/toxics6030035

15. Copper: Health Information Summary, Environmental Factsheet, New Hampshire Department of Environmental Services, ARD-EHP-9, (2005).

16. Svetlana Lutsenko, Natalie L. Barnes, Mee Y. Bartee and Oleg Y. Dmitriev, Physiological Reviews, 87, 1011(2007), DOI:10.1152/physrev.00004.2006

17. Vishal Desai, Stephan G. Kaler, The American Journal of Clinical Nutrition, 88(3), 855S(2008), DOI: $10.1093 / \mathrm{ajcn} / 88.3 .855 \mathrm{~S}$

18. G. J. Fosmire, The American Journal of Clinical Nutrition, 51(2), 225(1990), DOI: 10.1093/ajen/51.2.225

19. Laura M. Plum, Lothar Rink, and Hajo Hasse, International Journal of Environmental Research and Public Health, 7(4), 1342(2010), DOI:10.3390/ijerph7041342

20. K. K. Das, R. C. Reddy, I. B. Bagoji, S. Das, S. Bagali, L. Mullur, J. P. Khodnapur and M. S. Biradar, Journal of Basic and Clinical Physiology and Pharmacology, 30(2), 141(2018), DOI:10.1515/jbcpp-2017-0171

[RJC-5570/2019] 